\title{
Bibliometric Analysis of Trends in Theory-related Policy Publications
}

\author{
Abitassha Az Zahra ${ }^{1,2}$, Achmad Nurmandi ${ }^{1,3 *}$, Christine B. Tenorio ${ }^{2,3}$, Riska Rahayu ${ }^{1,2}$, \\ Samantha Herector Benectitos ${ }^{4}$, Faye Lorraine P. Mina ${ }^{4}$, Ken M. Haictin ${ }^{4}$ \\ ${ }^{1}$ Master of Government Affairs and Administration, Universitas Muhammadiyah Yogyakarta, Yogyakarta, Indonesia \\ ${ }^{2}$ Jusuf Kalla School of Government, Yogyakarta, Indonesia \\ ${ }^{3}$ Doctoral Programs of Political Islam, Universitas Muhammadiyah Yogyakarta, Yogyakarta, Indonesia \\ ${ }^{4}$ Public Administration Department, Mindanao State University-Iligan Institute of Technology, Philippines
}

\begin{abstract}
This study's bibliometric analysis evaluates the scope and trends of theory-related policy publications in various international journals. The method used the Scopus search engine on random journals in identifying policy-related publications. The study also used a data visualization software called VOSviewer to analyze the results, underlying network linkages, and information production trends in policy analysis. The findings shows that only a few proportions of policyrelated researches apply theories in their study. Field-specialized journals were having practitioners publish less research as compared to interdisciplinary science and technology journals. This article calls for greater engagements among scholars, and for policy researchers to more explicitly consider how their work might contribute to the understanding of the policy challenges. The findings also shows that it is important to recognize the approach and theory behind policy development to determine the incremental nature of aspects involved in policy development. It is extremely valuable to be clear that if one deals only with conceptual level of policy research without testing those ideas against independent empirical information, then scientific theory development is not possible. Thus, failure to consistently and clearly make theory connection towards policy research is a lost opportunity for scholars to influence policy thinking and public argument.
\end{abstract}

\section{Keywords:}

Policy Research;

Policy Thinking;

Higher Education;

Bibliometric;

VOSviewer.

\section{Article History:}

$\begin{array}{llll}\text { Received: } & 01 & \text { November } & 2020 \\ \text { Revised: } & 04 & \text { January } & 2021 \\ \text { Accepted: } & 19 & \text { January } & 2021 \\ \text { Published: } & 01 & \text { February } & 2021\end{array}$

\section{1- Introduction}

According to Zainab et al. (2009), studies "when journals are studied bibliometrically, it builds a portrait of the journals, offering important description that is beyond superficial." This tool can denote the journal's maturity, quality, and productivity in any field, country, or region [1]. A highlight of research orientation information is also developed to disseminate and influence authors' choice to communicate information associated with their needs [2, 3]. Therefore, a bibliometric study is a helpful tool used to understand the growth and dynamic of scientific literature. This study's bibliometric analysis provides a quantitative knowledge of scholarly literature in different theory-related policies on various international journals.

Although there is a vast literature on policy research across fields of social science, particularly in science and technology studies, sociology, social policy, political science, and public management, only a minimal variety of these

*CONTACT: Nurmandi_achmad@umy.ac.id

DOI: http://dx.doi.org/10.28991/esj-2021-01261

(C) 2021 by the authors. Licensee ESJ, Italy. This is an open access article under the terms and conditions of the Creative Commons Attribution (CC-BY) license (https://creativecommons.org/licenses/by/4.0/). 
contributions develop guidance and practice on 'impact' due to the inadequacy of theorizing studies [4-6]. Therefore, in various international journals or fields of study, there is a wide gap in research policy, which has been perceived in both policy and scientific literature. The absence of theorizing policy-oriented research is the main concern of this study because it limits the various fields of studies, global understanding of diverse challenges, and policy-makers' capability to formulating strategies effectively [7-9].

The theory is fundamental to research, and vice versa [10]. Scientific theories link two separate domains and provide summaries, descriptions, explanations, and integration on research policies, as well as guidance for additional practice and study capable of providing additional understanding [11, 12]. Theory is important in organizing, testing, summarizing, reevaluating, relating, and attempting to understand and explain things important for all humans in their daily aspect of lives $[13,14]$. This is contrary to the opinion that theory is "not relevant," "not needed," "dry," or "unimportant for the average person." Kurt Lewin (1951), a famous thinker and psychologist, stated that nothing is as valuable as a good theory [15]. This is accurate in regard to scientific theory, however theory building is also an essential feature of everyday living $[15,16]$. Therefore, there are some clear differences between the use of theory-related policy in scientific research and everyday life. Therefore, theorizing is the process of systematically organizing and developing ideas to explain phenomena, and a total set of empirically testable and interconnected ideas formulated to explain phenomena [17]. It is extremely valuable to be clear that when one deals with the idea or conceptual level without testing the independent empirical information, then scientific theory development is impossible [18, 19].

Weiss $(1977,1979)$ stated the concept associated with the enlightenment in the policymaking function of knowledge [21, 22]. According to Weiss, knowledge shapes policy from the various diffuse processes, which overlaps networks that influence broader, incremental, and frequent conceptual variation [20, 23]. Radaelli's (1996) concept of 'knowledge creep' is one of the numerous recent conceptualizations used to establish this idea [24]. This is in accordance with the similar assumptions of ideational theories of policy change [22, 23]. In addition, these accounts' stated that theory affects policy over prolonged periods through continuous changes in ways of thinking as well as the actor's perception. This body of work suggests that assessments aimed at tracing the development of theory-related policy are likely to ignore potentially broader and more diffuse kind of conceptual influence.

This study explored the influence of theories in policy research, which was formerly criticized for lacking a unique methodology and a scientific theory that covers the whole policy process [27]. This study was carried out to identify the policy research thematic trends in different journals. The authors examined the policies related to theory from journals of different fields of study to determine and explore the scope and theories used in their investigations. This research utilized the Scopus search engine to classify related policy publication on random journals. Furthermore, VOS viewer data visualization software was used to analyze the results, underlying network linkages, and information production trends in policy analysis. The size and evolution of scientific activity, the nature of existing inquiry in policy research, and the knowledge transfer pattern that employs theory were analyzed.

This research described the various field of studies theory related to policy research and suggested strategies that can be utilized by scholars to understand the resolution of modern policy challenges. This analysis also showed that it is important to recognize the approach and theory behind policy development to determine the incremental nature of aspects involved in policy development.

\section{2- Research Methodology}

The Scopus search engine was used between August and September 2020 to identify broad literature on a certain theory's policies. Scopus is one of the most extensive citations and abstract databases of peer-reviewed literature, such as scientific journals, books, and conference proceedings [28]. Although several publications discuss various policy theories, this analysis focuses only on international journals, which were extracted using the Scopus search engine and Sci-Hub because the documents were not free. Nevertheless, a considerable cross-indexed proportion of policy research is in Scopus. This is not an all-inclusive research because it enables the practical representation of the state of policy research related to applying theories in various journals. Furthermore, the search string was limited to obtain the most appropriate record pertaining to policy based on publication year. Articles published from 2010-2019 garnered the highest number of publications.

The initial search identifies publication related to policy researches in their titles, abstract, or keywords: "policy research*" OR policy theory*" OR "policy*" OR "theory*" OR "policies" OR "regulation*" OR "policy relation*" OR "public policy*" OR "policy studies*." A repetition of the search was used in the following query to identify a subcategory of publications that refer to the application of theories based on publication year: ("policy research*" OR policy theory*" OR "policy*" OR "theory*" OR "policies" OR "regulation*" OR "policy relation*" OR "public policy*" OR "policy studies*") AND ( LIMIT-TO ( PUB YEAR, 2010) OR LIMIT-TO ( PUBYEAR, 2011) OR LIMIT-TO ( PUBYEAR, 2017) OR LIMIT-TO ( PUBYEAR, 2018) OR LIMIT-TO ( PUBYEAR, 2019). 


\section{2-1- Inclusion and Exclusion}

A systemic review approach, guided by a set of inclusion and exclusion criteria, was used to filter studies irrelevant to the objectives, questions, and scopes on bibliometric search. Therefore, successively shortlisted publications on policy researches in different international journals are obtained, which comprises of both subscribed and open access publication year (2010-2019). This includes book and their chapters, review editorial material, conference proceedings, industry reports, journal articles, and trade publications. However, items such as letters, book reviews, reprints, news article, errata, notes and bibliographies, short surveys, and conference reviews were omitted. The search results used no geographical restrictions and language. In addition, a process of shifting the abstracts and full texts to determine relevant studies were equally carried out by the second and third authors, while the first audited and reviewed. Based on the identification of publications, only those that precisely concentrated on policy research and obviously considered applying theories in their investigation were included. These publications are associated with vague policy implications, a loose reference to policy research, without fundamentally engaging policy substances. Furthermore, prior to extraction, duplicate records were omitted before the design of a data extraction template to draw out relevant data capable of significantly informing the synthesis process.

\section{2-2- Data Extraction}

At the end of each search, screened results were saved into separate marked lists with the Scopus used to visualize outputs, categorize, and rank results. The extracted data were imported and cleaned into VOS viewer - a program visualization data to establish and view network maps based on collected data [29].

\section{2-3- Analysis}

The published articles were categorized and reviewed through many variables. The authors appraised the origin and state of the research discipline in terms of citation metrics, top publication, journals, types of publications, countries or regions, research areas, and identifying patterns in the production of knowledge related policy research theories. A bibliometric review using VOS viewer was used to identify published literature and primary network linkages. Using bibliometric techniques, the research trends in health, information technology, education, monetary, supply chain management, fiscal, foreign, and even public policies were explored. Therefore, similar methods were applied in examining the literature on policy implementation, evaluation, learning, the evolution of science and technology, and sciences.

Network maps were also designed to examine the publication's connectedness through common keywords, shared content within publication titles and abstracts (co-occurrence), and assessments of the frequency of simultaneous citation (co-citation).

\section{3- Results}

Preliminary studies consisting of 75 articles, 45 proceedings papers, 3 handbooks focused on theory-related policy in any field of studies. However, only 40 articles, 60 proceedings papers, and 3 handbooks addressed or applied policyrelated theories or frameworks in their investigations. Therefore, most authors failed to establish their work in the context of theorizing policy research, despite further knowledge of the effects and phenomenon that hypothetically influence policy.

Theorizing policy research plays a significant impact on the way policy-makers think [5]. Furthermore, the role of policy theories guides general behavior [4]. Studies related to this subject have been analyzed in various ways. For example, Weible et al. (2013) discuss how to use policy theory to influence the US policy process, while Lasswell (1970) identified 'a distinctive outlook' in US policy science $[11,19]$. With the growing focus on globalization, policy-makers and academic scholars became more fascinated in recognizing the quality of primary influence and dealing with national economies, international politics, and welfare systems [30]. This led to an increase in policy researches in different fields of studies after 2000. Subsequently, their increase in trajectories has continued, except that overall policy research is growing much faster than those applied in the investigation, as shown in Figure 1. 


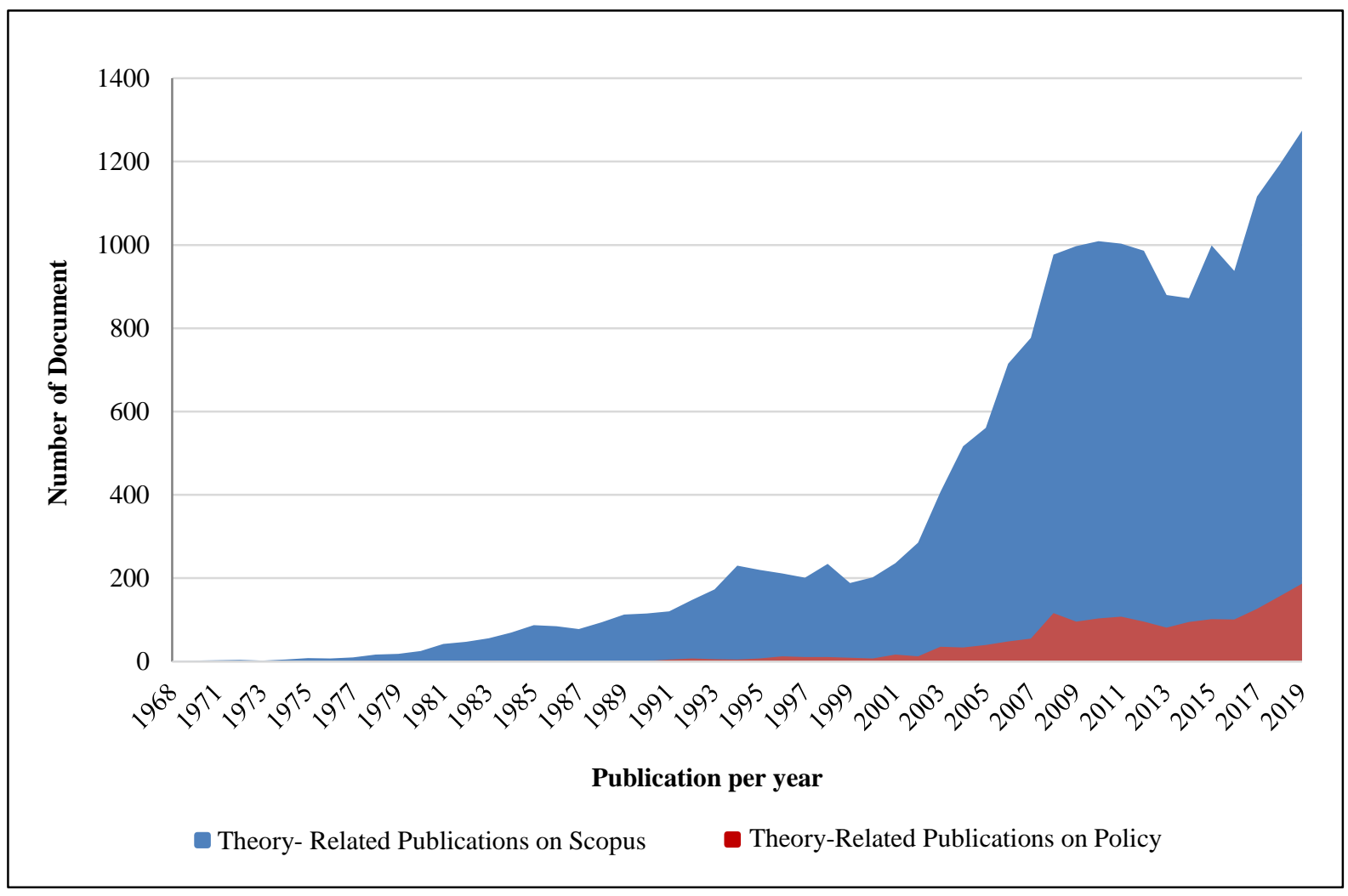

Figure 1. Publication trends in related policy research.

\section{3-1- Geographical Distribution}

The policy research production in various journals of different studies is geographically uneven, with some countries producing significantly more than others. Approximately $30 \%$ of this policy originated from authors based in the United States (US). At the same time, China, as a non-western country, has significantly high policy research (one-fifth) than the UK and Canada. This reflects China's strength of departments, which consistently focused on policy, think-tanks and research centers, and research-driven governance and policymaking cultures. Surprisingly, the UK's collaboration with US scholars in the 1970s and 1980s [28-31] developed a range of theories and models of relationship that drives policy to stimulate research capable of producing immediate solutions. However, over the past few years, only oneeighth of the policy researches originate in the UK, Canada, and Australia's address theory, as shown in Table 1. On the other hand, Germany, France, Netherlands, and Italy, produced more detailed policy research, with one-sixth related to theory.

Table 1. Country affiliation of authors publishing the most theory related policy research (selected list).

\begin{tabular}{ccc}
\hline Author country & $\begin{array}{c}\text { Number of document policy- } \\
\text { related publication }\end{array}$ & $\begin{array}{c}\text { Proportion of total related policy research } \\
\text { theory research output }(\%)\end{array}$ \\
\hline US & 1221 & 30 \\
China & 866 & 21 \\
UK & 508 & 12 \\
Canada & 264 & 6 \\
Australia & 230 & 6 \\
Germany & 177 & 4 \\
France & 158 & 4 \\
Netherland & 149 & 4 \\
Italy & 146 & 4 \\
Taiwan & 106 & 3 \\
India & 102 & 2 \\
Iran & 84 & 2 \\
South Korea & 82 & 2 \\
\hline
\end{tabular}




\section{3-2- Publication Venues}

Policy publications are rigorous in interdisciplinary science and technology, as well as social policy. Meanwhile, journals like Transportation Research Part a Policy and Practice, International Journal of Production Economics, Proceedings the IEEE Conference on Decision and Control, Communication in Computer and Information Science, Social Science, and Medicine and ACM International Conference of Proceeding Series have a great amount of policy research with less significant theory related to work policy, as shown in Table 2. However, this is not surprising because the editorial and audience target journals to scrutinize manuscript for significance and orientation heading to selfselection. Therefore, scholarship and leadership in policy research related to the theory are shared between the technical and applied categories that are policy-oriented.

Table 2. Theory-related policy research publications on different international journals (selected list).

\begin{tabular}{llc}
\hline Source Title & $\begin{array}{c}\text { Number of Policy-related } \\
\text { publications }\end{array}$ & $\begin{array}{c}\text { Proportion of Policy Theory } \\
\text { publications (\%) }\end{array}$ \\
\hline Energy Policy & 61 & $19 \%$ \\
Sustainability & 43 \\
Journal of Cleaner Production & 43 \\
European Journal of Operational Research & 31 \\
ACM International Conference Proceeding Series & 26 \\
Social Science and Medicine & 25 \\
Communications in Computer and Information Science & 25 \\
Proceedings of the IEEE Conference on Decision and Control & 21 \\
International Journal of Production Economics & 20 \\
Transportation Research Part a Policy and Practice & $19 \%$ \\
\hline
\end{tabular}

\section{3-3- Authorship}

The authors published articles in a different international journal associated with the theory related to policy research, as shown in Figure 2 (Wang, J. (33), Lee, J. (30), Lee, Y. (29), Wang, X. (28), Zhang, J., Zhang, X. and Wang, Y (25 each), Liu, X., Liu, H. and Liu Y (23 each) and Li, X and Wang, Z (21 each)). A majority of these authors are affiliated to a handful of institutions with five or more theory-related policy research publications, as shown in Figure 3 . These include the Institute of Technology Beijing (8), University of Maryland (7), Institute of Automation China (6), University of Jiatong (6), and Institute of Economic Beijing (6). The volume of policy research related to theory centered within a relatively small group of scholars working on a few academic institutions operate in mixed-disciplinary teams through interdepartmental collaborations.

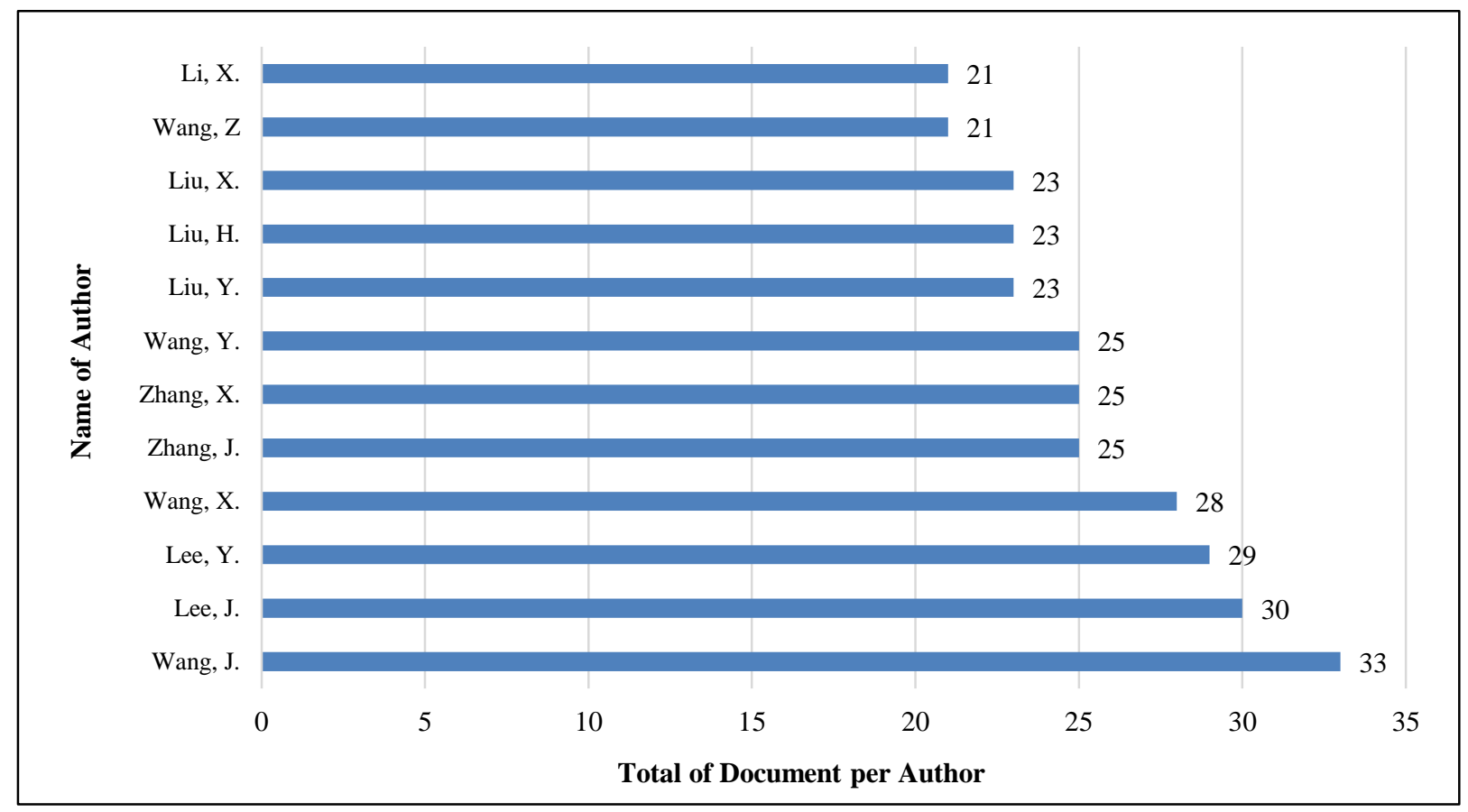

Figure 2. Authors producing most theory related publications. 


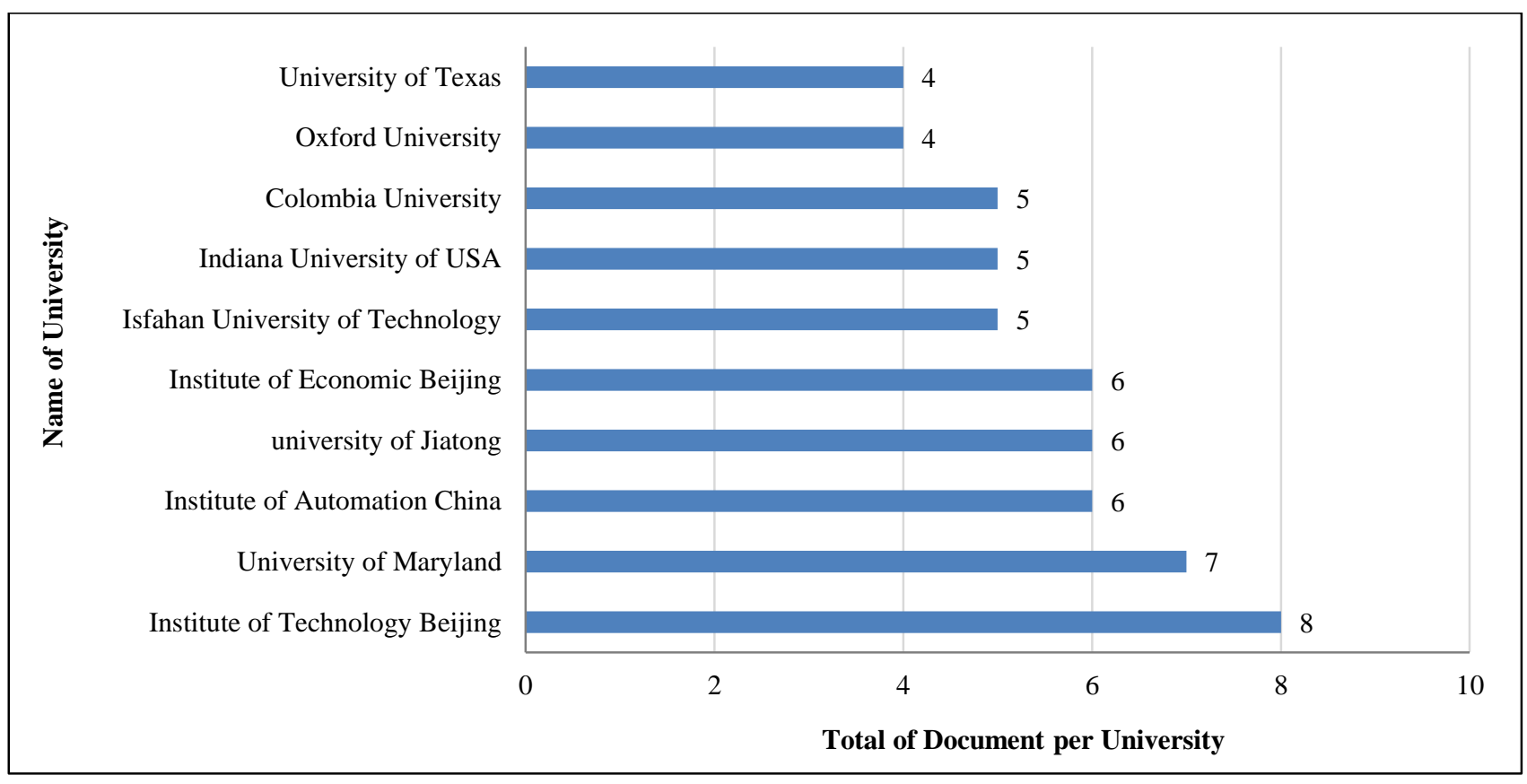

Figure 3. Institutional affiliations of authors producing most theory-related policy research publications.

\section{3-3- Areas of Policy Focus}

The number of policy researches has enormously appeared in the area of Information System Security. According to the Military and Associated Terms of the US Department of Defense Dictionary, information system security is "the protection of information and system against unauthorized modification or access, in processing, storing, or transmitting the denial of service to authorized users [34]. Information security includes measures used to detect document and counter threats. It is a combination of communications and computer security [32, 33]. At its most basic level, information system security keeps confidential information [34, 35]. Currently, businesses in the United States determine new rules and regulations capable of protecting consumer confidentiality. According to data from the Nilson report, the United States accounts for only $27 \%$ of credit card transactions globally, with $47 \%$ victims of fraud. Breaches such as these have reduced consumer confidence and have moved the topic of the safety of personal information to the forefront of many promising organizations to keep the data of its customers secure from hackers.

Studies on information system security inclined to focus on cross-cutting similar themes, such as compliance, violations, pieces of training, and understanding security policy. Furthermore, many modern organizations' accelerated use of Information technology has made information residing in these technologies vulnerable to security risks [39]. Most of these vulnerabilities emanated from policy violations and lack of policy compliance specified in organizational guidelines and policy documents [37, 38]. Information security policy documents serve as a good starting point in addressing concerns regarding violations. These policies address resolutions on appropriate and inappropriate actions by employees [42]. Research has shown that employees rarely follow recommended information security procedures irrespective of their awareness levels [9].

Information Security (IS) policy violations by employees have considerably increased IS vulnerabilities and has contributed to over half of all reported security breaches $[9,40]$. research has equally shown that employees deliberately ignore prescribed IS policies [41, 42]. Therefore, research fails to recognize the importance of human behavior, the organizational structure where behavior is carried out, and the policies in place shape behavior outcomes [46]. These policies' shaping behavior do not always reach full potential and thwart these attempts, such as reactive computer abuse. Sometimes employees are motivated to react negatively to policies, as shown by studies examined using the reactance model [41]. Furthermore, it is difficult to determine and measure policy violations, whether by intent or inadvertently. However, various theories, such as accountability theory, have been used to explain how intention positively influences accountability, decreasing intention to violate policies [45].

Furthermore, research associated with Information System Security has reviewed the significant need for IT security and information assurance to reduce cyber-attacks, computer/server malfunction, or theft by technology experts, thereby increasing the demand for trained professionals. The other area encompasses related policy research, including water quality, internet use, game theory, energy-saving, inspection, and pricing policies. These inquiries have received inadequate attention aligning ideological or theorizing policy researches rather than a technical approach. 


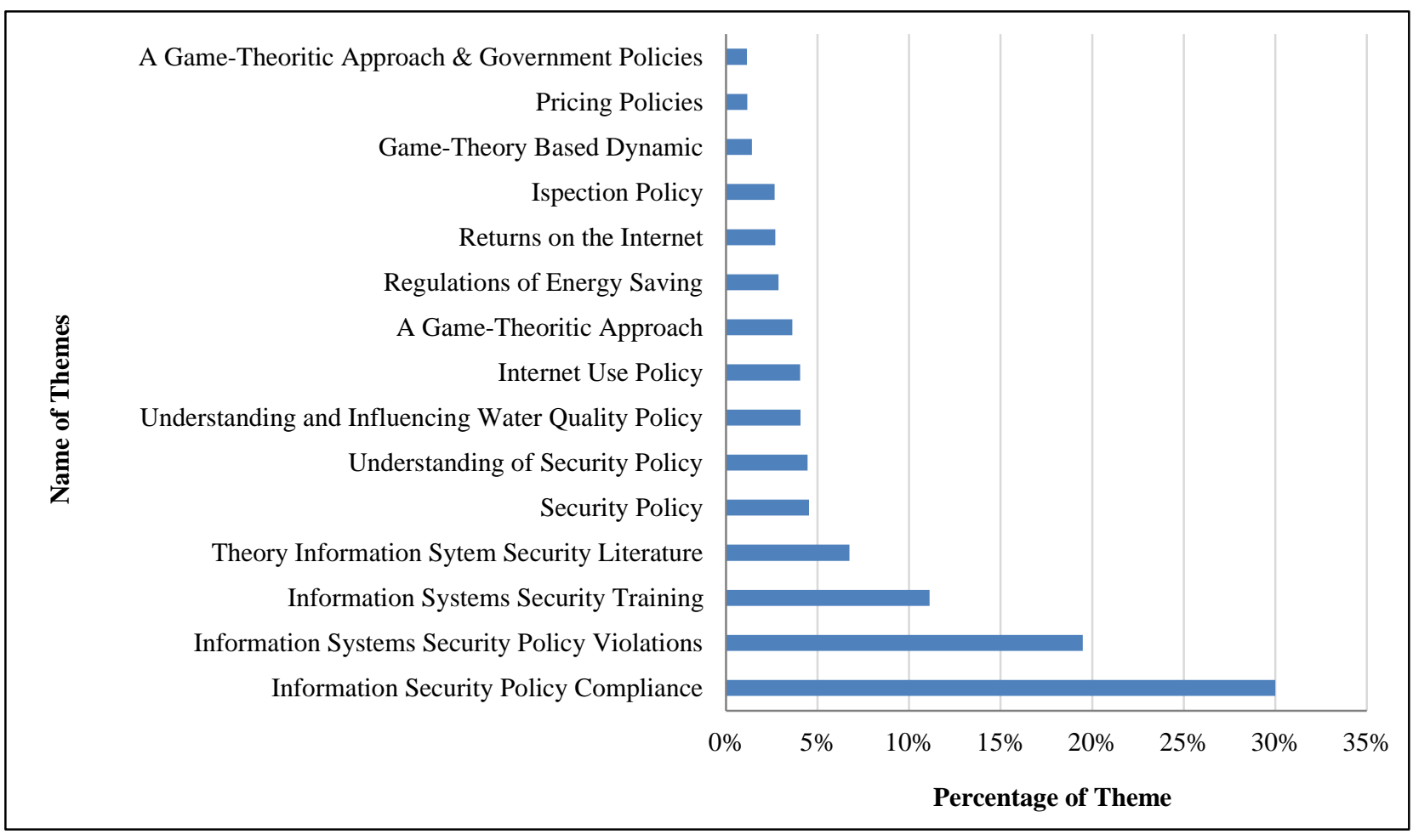

Figure 4. Frequently occurring themes in theories related to policy researches.

\section{3-4- Network Linkages in Policy Research Theories}

Table 3 provides a picture of the most cited policy-related publications and the key issues they have been discussed. These papers have, in turn, driven others and led to an increasingly critical mass policy work, as shown in Fig. 5. The gulp of scholarship in the field is determined by researchers' conglomerates based on their centrality to specific knowledge issues, such as information system security, internet use, security policy, and game theory, as shown in Figure 6.

The result shows that policy-related production is scattered across various journals, depending on the nature of the research subject and paradigms employed. Figure 7 recognizes distinct journals category where theory-related policy research appeared in the top five international journals, namely Energy Policy, Policy Studies Journal, European Journal of Operational Research, American Economic Review, and Social Science and Medicine.

The top five journals scope of background is discussed as follows:

Energy Policy is a peer-reviewed international journal addressing energy supply policy implications and uses obtained from social, economic, environmental, and planning aspects. The topics of particular interest within this broad spectrum include environmental regulation and energy, the quality and efficiency of energy services, energy supply security, technological innovation and diffusion, the effectiveness of market-based approaches, and governmental interventions voluntary initiatives where the broader policy implications can be identified. It is mandatory to reinforce policy prescriptions by balanced appraisal and rigorous analysis. The Policy Studies Journal (PSJ) is a public policy research premier channel. PSJ is best considered an outlet for empirically and theoretically built research on the policy process and analysis. The aim is to publish articles that advance public policy theory, openly articulate data analysis and collection methods, and provide clear descriptions of how their work develops the literature. The European Journal of Operational Research (EJOR) publishes high-quality original manuscript that promotes the methodology of Operational Research (OR) and the practice of decision making. The American Economic Review (AER), established in 1911, is a general-interest economics journal and among the nation's oldest and most respected scholarly journals in the economics profession with over 100 years of publishing. According to studies, Social Science and Medicine provides an interdisciplinary and international forum for the dissemination of social sciences on health. The journal publishes material related to any aspect of health from a wide range of social science discipline (economics, epidemiology, anthropology, policy, geography, sociology, and psychology) and material relevant to the social science from any concerned professions with mental and physical health, clinical practice, health care, organization, and policy.

This is significant because it presents how scholarship is distributed across a wide disciplinary spectrum and showcases certain unscientific relationships. For example, the theory-related to policy research is more frequently discussed in the context of Information Technology, with specificity on Information System Policy, compared to related social sciences journals. 
Table 3. Most cited theory-related policy research publications.

\begin{tabular}{ccc}
\hline Author & Issued Discuss & Total Citation \\
\hline Bulgurcu b. (2010) & Information Security Policy Compliance & 847 \\
Siponen m. (2010b) & Information Systems Security Policy Violations & 550 \\
Punhakainen. P (2010) & Information Systems Security Training & 314 \\
D'arcy J. (2011) & Theory Information System Security Literature & 190 \\
Siponen m. (2010a) & Security Policy & 128 \\
Son j.y (2011) & Understanding of Security Policy & 126 \\
Blackstock. K.1 (2010) & Understanding and Influencing Water Quality Policy & 115 \\
Li, H (2010) & Internet Use Policy & 114 \\
\hline
\end{tabular}

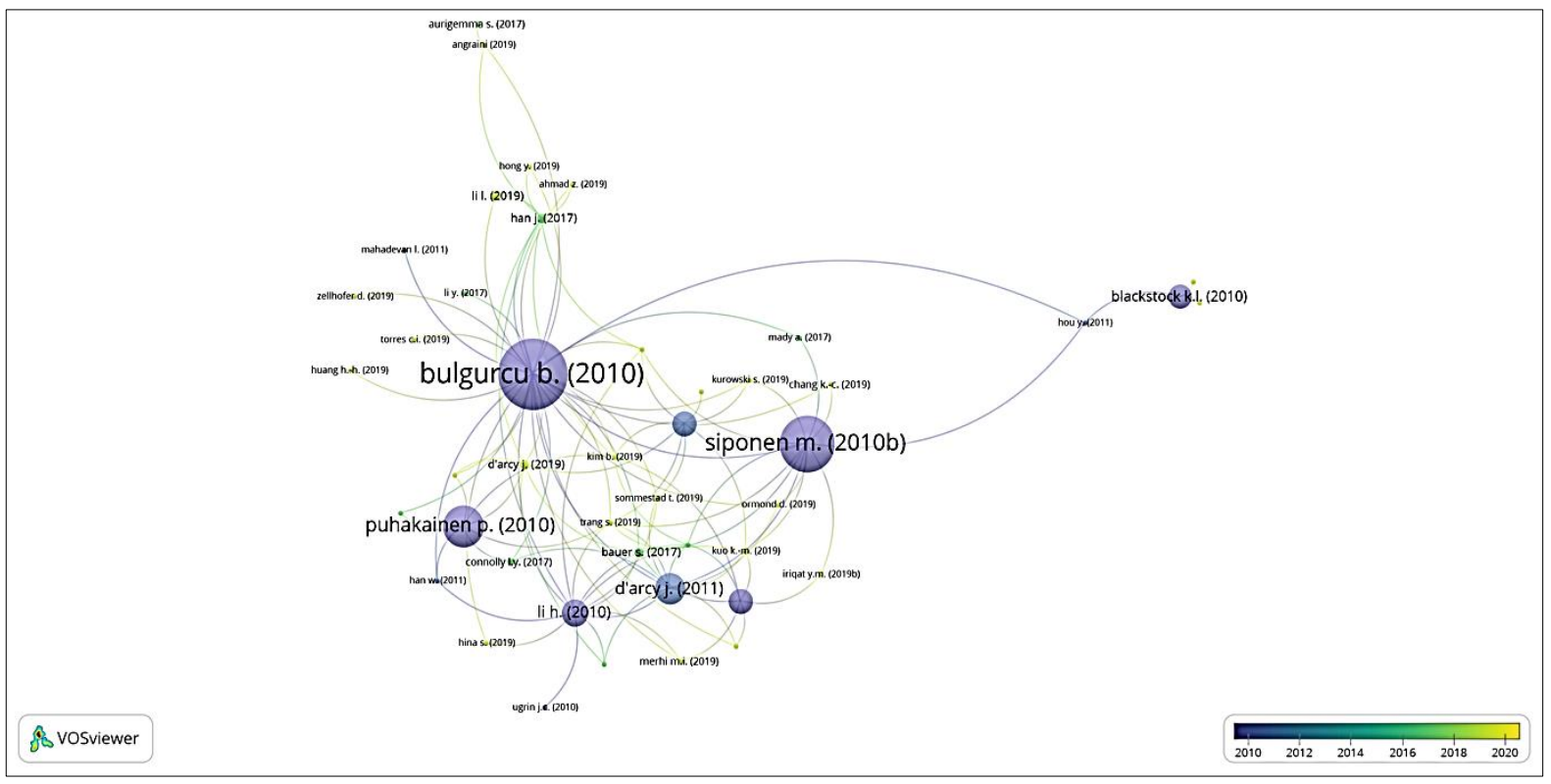

Figure 5. Citation network of theory related policy publications. Note: The figure shows how commonly publications (with at least ADD citations) get cited by others in the network. Nodes denote their linkages and publications and convey citation relationships. Larger nodes show publications with more citations. Publications with close citation relationships are clustered together in nodes of the same color.

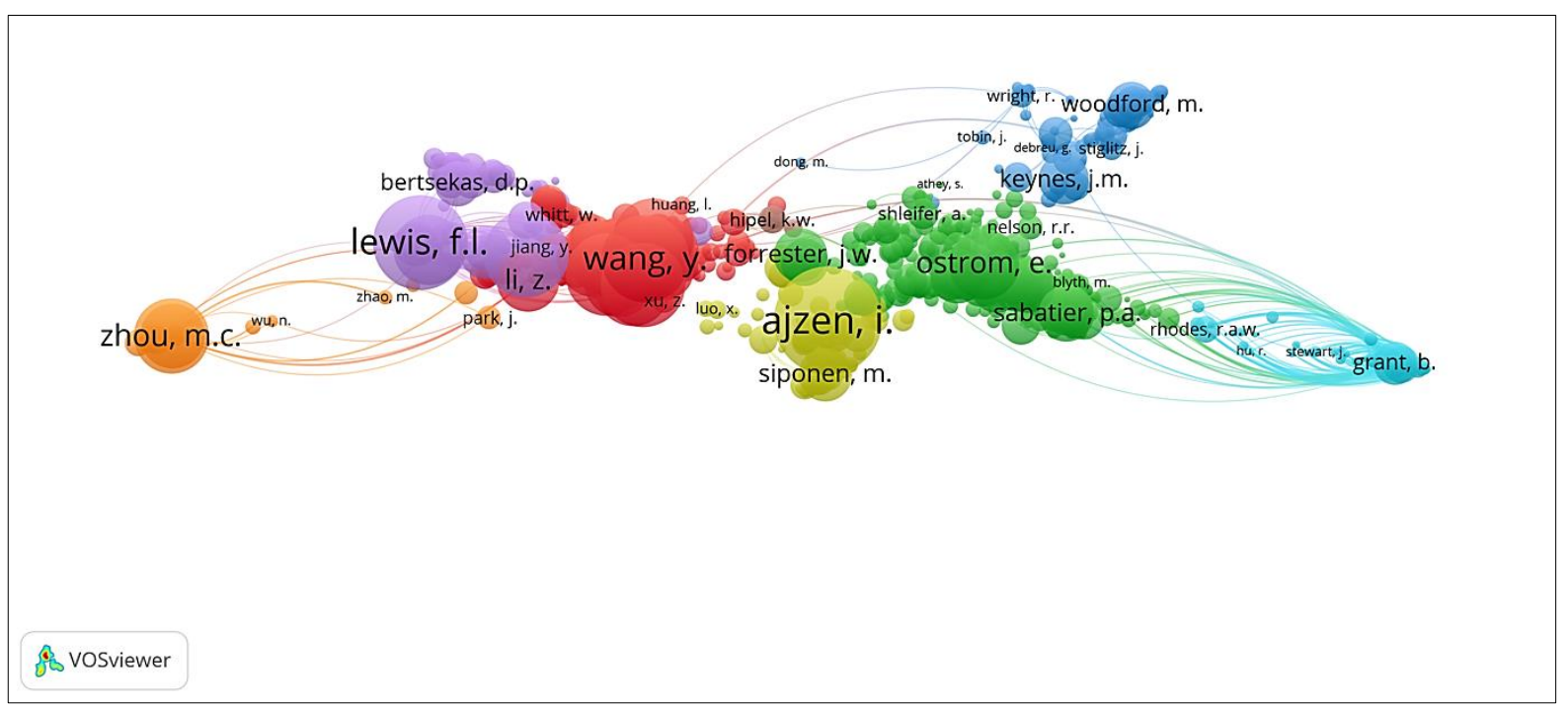

Figure 6. Co-citation network of scholars with theory related policy publications. Note: The figure shows how commonly scholars (with at least ADD citations) are cited together in publications. Nodes denote authors, and their linkages convey co-citation relationships. Larger nodes present authors with more citations. Link strengths indicate the frequency with which they are co-cited. Scholars that are co-cited often are clustered together in nodes of the same color. 


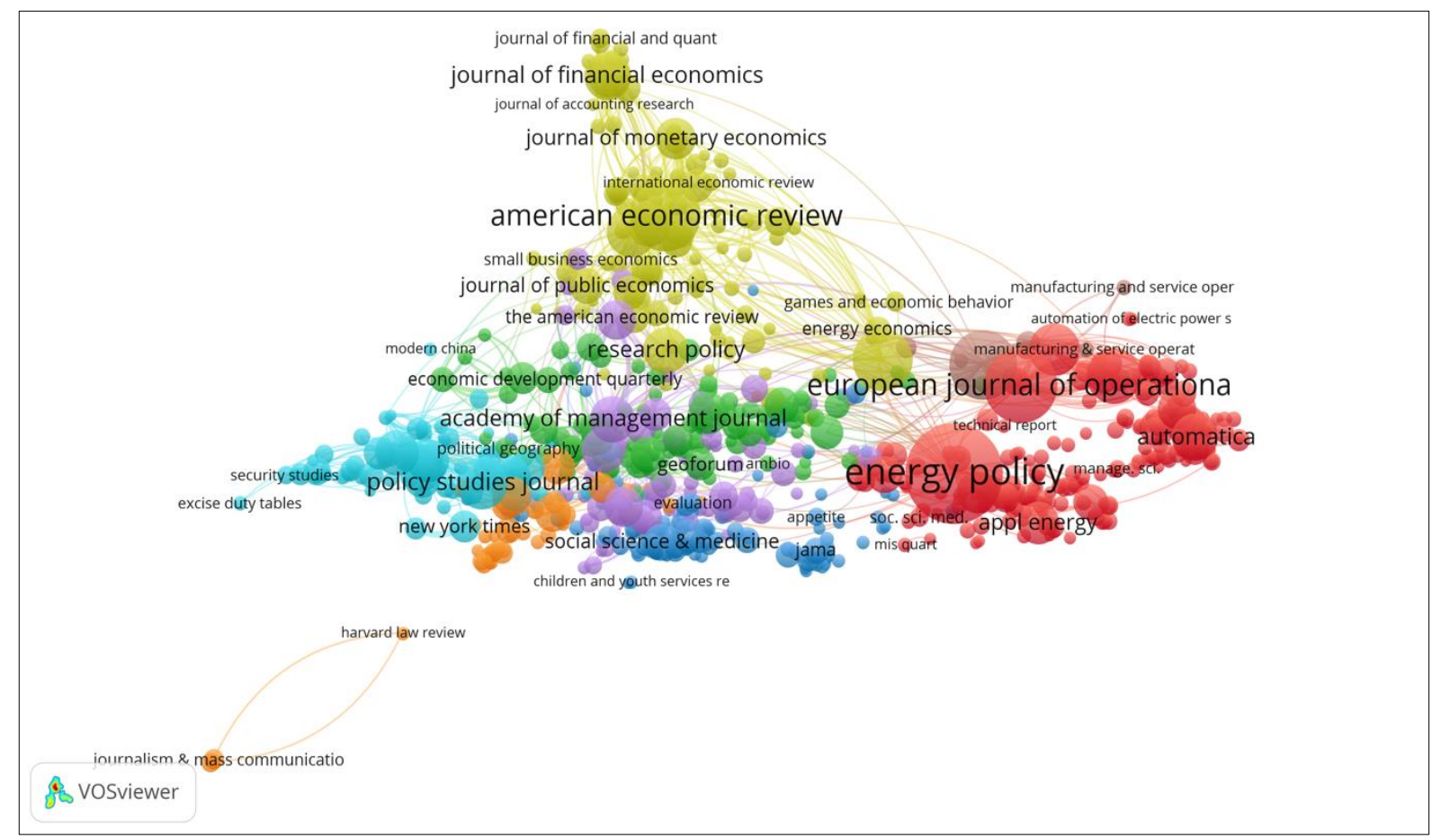

Figure 7. Co-citation network of journals publishing theory-related policy research. Note: The figure shows how commonly journals (with at least ADD citations) are cited together in publications. Nodes denote journals, and their linkages convey co-citation relationships. Larger nodes present journals with more citations. Link strengths indicate the frequency with which they are co-cited. Co-cited Journals often are clustered together in nodes of the same color.

\section{3-5- Thematic Evolution of Policy Research Theories}

This research categorized the key themes in existing theory related policy research, with figure 8 showing a network analysis trend that features the difference between the old and new research course. These include a renewed focus on game theory, system dynamics, public policy, institutional theory, health, foreign, monetary, reinforcement learning, and development policies in different studies, with game theory as the most occurred keyword. Game theory has long been utilized to support a thorough analysis of actors' interaction processes. The majority of public policies are formulated and implemented in multi-actors networks. Therefore, in the network society, policy formulation and implementation are developed by the interaction between multiple actors. According to Bardach (1977), this multi-actor dimension is not new and not implemented for policy formulation [47, 48]. However, the importance and visibility of these networked attributes are growing.

Game theory is the most trend keyword in theory-related policy research. It formalizes a game metaphor used to study strategic interactions among actors by ensuring that they organize their behaviors in accordance with the various strategies [49]. Game theory offers a technique used to develop formal models of such situations by considering a limited number of actors or coalitions. Game theory functions in an assumption that the outcomes of interactions can be explained from rational choices by individual participants [50]. It is used in institutional and policy analysis as well as in social science. It is utilized to study how certain contextual and rule factors shape incentives for behavior, and the evolution of institutions over time, which can be explained from actors that look for cooperative solutions for social dilemmas [48, 51-53]. Furthermore, desk-studies also suggest that formal game theory models can create a range of realworld games, which can be used to explore fairness and allocation questions in the distribution of values among actors $[53,54]$.

Although this research analysis found that most theory-related policy researches are prevalent in science and technology studies, the Game theory denotes its usefulness in a growing complex institution, technologies, and cultural norms that have existed in human societies. For example, internet technology greatly facilitates buyer-seller transactions and complicates further by increasing fraud and cheating $[46,47]$. This presents scholarships evolving with global shifts in policy agendas and reorientation towards theorizing policy research within the current decade. 


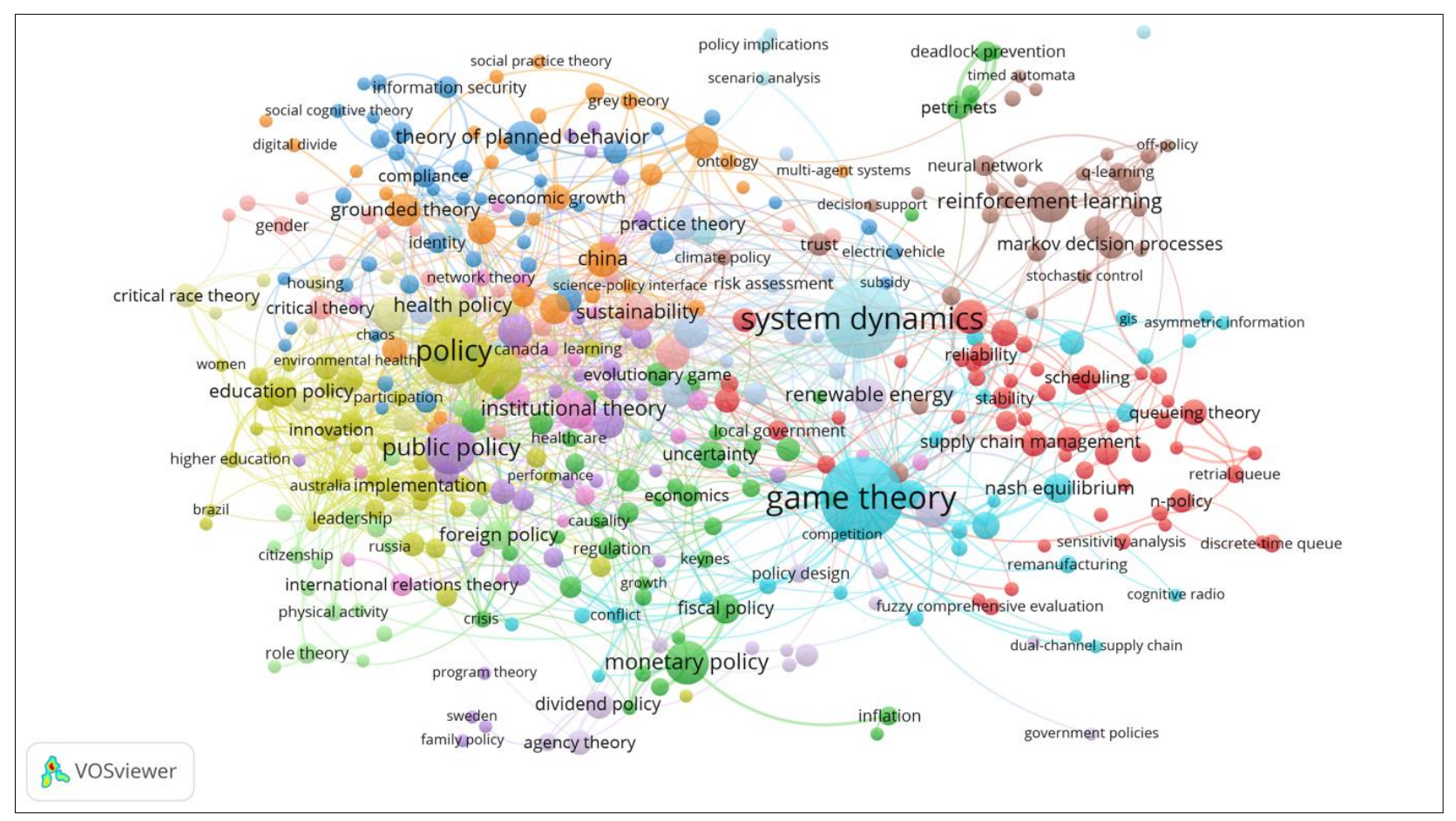

Figure 5. Co-occurrence network of the keyword in theory-related publication on a different international journal. Note: The figure illustrates the author relatedness designated and author indexed keywords (with at least ADD occurrences) based on how frequently they occur in the same publications. Nodes represent linkages and their keywords and denote co-occurrence relationships. Larger node means keywords with more occurrences. Link strength indicated the co-occur frequency. Keywords that co-occur frequently are clustered together. Nodes are colored based on the frequency with which the keyword occurs in a publication in various years. Keywords occurring with greater frequency in recent publications are colored lighter than those frequently occurring in the past.

\section{4- Discussion}

The finding's validity is narrow by the intrinsic bibliometric analysis keyword-based weaknesses. The authors carried out the research with explicit operationalization and equally confine of policy research, which led to a number of policyrelated works. Furthermore, this research concentrated on published academic studies, with the outputs produced by non-profit organizations, non-governmental agencies, governmental departments, and think tanks. Notwithstanding these methodological bounds, there are evident patterns and movements in the data that relate, others, thereby lending some interesting ideas.

Only a few amounts of policy researches in different international journals explicitly address theorizing investigation. Furthermore, a few types of research place their investigation in the context of modern theoretical arguments and implication or deliberate the theoretical contribution. The lack of theorizing policy is not new to another field of studies, however, it is prevalent in other science and technology-related disciplines, such as information technology [46, 48], information system security [57], internet use [58], energy and water sector studies [59]. This is because theory-related policy study is a necessary applied component of science and technology studies and posits a more complex interrelationship between knowledge production and governance. Therefore, it is a possible concern because even though a few research numbers are implicitly theory related, failure to make the policy test against independent empirical information is a lost opportunity for scientific theory development. For example, research on care policies has highlighted the issues that consider discoursing a transversal factor connecting actors and institutions involved in policy implementation [30]. However, it does not adequately address the idea that is also evident in theories or the gap in a theoretical dialogue of gender and politics.

Furthermore, theory related policy shows how science produces social problems through its various technical and scientific innovations [60]. The development of progress in science and technology produce a continuous stream of new issues and solutions. In areas that are highly dependent on science and technology, such as health, energy, agriculture, and defense. In addition, this develops policy associated with science to catch up with attaching and regulate new technologies when produced. Furthermore, while policy researched in different fields of the study showed interdisciplinarity, there is a little theoretical and conceptual crossover between contemporary scholarship in policy science and the different disciplinary perspective of policy studies [50, 52]. This is possible because non-policy background authors have carried out most policy research with their individual different disciplinary foundations and few theoretical groundings. Therefore, the demand for ever more knowledge problem-solving is effectively built into 
the policy-research structure [53-55].

Efforts to draw and engage policy theory have been made. For instance, Son (2011) reported the employee's securityrelated rule understanding behavior with an approach rooted in an intrinsic motivation model [64]. Hermans et al. (2014) used the game theory in an evaluation of coastal policy implementation in the Netherlands to open up the black-box of policy implementation, while Blackstock (2010) used psychological and institutional theories of behavior in understanding the best influence farmer behavior in order to mitigate diffuse pollution [55, 59]. D'Arcy et al. (2011) draw attention to using the Deterrence theory, commonly used in studies associated with information system (IS) security [61]. The theory predicts that illicit behavior can be controlled by the threat of severe, certain, and swift sanctions. Li et al. (2010) carried out research that analyzed rational choice theory and examined how employees' intentions comply with the use of internet policy driven by personal norms, cost-benefit assessments, and organizational context factors [62]. Safarzadeh (2019) applied the game-theoretic approach to assess residential energy-efficiency programs considering rebound, consumer behavior, and government policies. Although such cases are uncommon, these articles are fine examples of how policy-oriented theoretical frameworks offer research potential lensed to explore the essence of policy issues and assess solutions' contextual efficacy [63].

While policy research appears to spread more rapidly on average, theory-related policy publications in various international journals are generally less common. Differences in the policy research geographical distribution production are fascinating. Certain countries show considerably higher performance than others due to the high capital allocation rates to policy-oriented agencies. Research projects are further prioritized to showcase the social effect of grants, the quality of their policy faculties, institutions, and think tanks, as well as a tradition of research-driven governance and policymaking. Nonetheless, theory related policy research is more frequent in some fields and appear to exist for certain journal groups.

An example is the policy publications in multiple disciplines studies and science and technology journals, with the publication of field-based journals. A small number of overall theory-related policies is published in public administration and political science, in line with the research carried out by Hall and Jenkins' (2004) regarding the distinct lack of theoretical commitments by policy sciences and public scholars [65]. Theory-related policy research is centered within a relatively small community of academics within the diverse association of research groups. This culminated in the development of independent strands of policy scholars.

Some fields, such as information security systems and information technology, have gained much more attention. The emphasis in theory-related policy research has shifted to address newer themes, particularly information technology, internet use, and information system impacts on human behavior and health education. Furthermore, science and technology scholars have shown how science produces theories and knowledge that help define social problems and proper responses. It also produces machines, skills, instruments, and technology deployed in governance [56, 57]. Besides, policy studies have drawn existing empirical studies and literature in the field to examine many organizations that are often considered the weakest link in information security. Therefore, it is also a great asset in determining less risk-related information security [56]. Puhakainen (2010) explored employee noncompliance with information system security policies as a key concern for the organization and suggested that users do not comply with IS security policies, security solutions lose their efficacy [65]. Similarly, Han (2017) showed how organizations are trying to induce employees to comply with information security policy (ISP) as organizational damage to information breach incidents become serious [57].

Furthermore, it is also essential to explore the body of theories-related to the policy process to make health education and promotion research [4, 58, 59]. Birckmayer and Weiss (2000) used a Theory-Based Evaluation approach to expand the significance of the rigorous application of theory to address social problems [20, 22]. The theory also provides key principles to promote health, along with evaluation and development of health education. Gonzalez and Glantz authored a policy issue, which was used without adequate application of theories. They used a case study on the failure of policy in the Netherlands, a cosigner of the Framework Convention on Tabacco Control, which passed comprehensive legislation that regulates all aspects of MPOWER strategy. It is assumed that the phenomenon under study explicitly selected an adequate theoretical framework in a theory-based policy evaluation approach. The professional and authors visualize that policies are made and implemented while applying political science theory claims for the classification of association between Mackenbach's (2004) policy implementation structures, outputs, and processes [70].

Nonetheless, such work offers realistic, evaluative theoretical frameworks for policy-makers to analyze the trends, factors, challenges and evaluate the currently proposed policy initiatives' consequences and effectiveness to create more appropriate enforcement solutions. Meanwhile, these reflect only a component of the extensive scope of theory related policy research, with the development indicating a change in scientific studies as well as the formulation of policies in different fields towards more action-oriented research, theoretical focus, problem-centric and reflective on the kind of research needed to resolve its policy challenges. This move reinforces the wider trends within policy science, thereby emphasizing the theoretical conceptualization of policy concerns and technical study. 


\section{5- Conclusion}

In conclusion, the academic literature was used to determine theory-related policy research. The study's first objective identified how much policy research publications explicitly apply theory in their investigations. The second objective outlined the contours of theory-related policy research and determined the policy's aspects being studied or overlooked. Therefore, this research reviews the state of theory-related policy. Generally, the study discovered that discussion on theory-related policy research is relatively limited, with lopsidedly divided towards selected policy areas. Hence, there is a need to apply a systematic and theory-driven approach in determining policy development effectiveness. The present study provided insights into theory-related policy researches in various international journals.

Furthermore, policy scholars need more significant engagements with explicit consideration of how their work contributes to the resolution and understanding of challenges. Meanwhile, theorizing policy research in various international journals is one of the tools used to carry out investigations and theory-related policy publications which span across other arenas with distinct problem perspectives and parameter solutions that influence policy-makers' capability to formulate strategies effectively. Furthermore, the analysis showed that it is important to recognize the approach and theory behind policy development to determine the incremental nature of aspects involved in the development.

\section{6- Declarations}

\section{6-1-Author Contributions}

Achmad Nurmandi conceived paper idea and synthesizing findings; Christine Tenorio contributed to organization of paper writing. Abitassha Az Zahra, Riska Rahayu, Samantha Herector Benectitos, Faye Lorraine P Mina, Ken M Haictin contributed to the journal collection and processing. All authors contributed to manuscript revision. All authors approved the final version of the manuscript and agree to be accountable for the content therein.

\section{6-2-Data Availability Statement}

The data presented in this study are available on request from the corresponding author.

\section{6-3- Funding and Acknowledgements}

The author(s) received financial support for the research from Jusuf Kalla School of Government, Universitas Muhammadiyah Yogyakarta, authorship, and/or publication of this article.

\section{6-4- Conflicts of Interest}

The author declares that there is no conflict of interests regarding the publication of this manuscript. In addition, the ethical issues, including plagiarism, informed consent, misconduct, data fabrication and/or falsification, double publication and/or submission, and redundancies have been completely observed by the authors.

\section{7- References}

[1] Zainab, A. N., Kevin Wan Utap Anyi, and Nor Badrul Anuar. "A single journal study: Malaysian Journal of Computer Science." arXiv preprint arXiv:1301.5375 (2013). doi:10.22452/mjcs.vol22no1.1.

[2] Liao, Huchang, Ming Tang, Zongmin Li, and Benjamin Lev. "Bibliometric Analysis for Highly Cited Papers in Operations Research and Management Science from 2008 to 2017 Based on Essential Science Indicators." Omega 88 (October 2019): 223236. doi:10.1016/j.omega.2018.11.005.

[3] Zhang, Nan, Shanshan Wan, Peiling Wang, Peng Zhang, and Qiang Wu. "A Bibliometric Analysis of Highly Cited Papers in the Field of Economics and Business Based on the Essential Science Indicators Database." Scientometrics 116, no. 2 (May 28, 2018): 1039-1053. doi:10.1007/s11192-018-2786-7.

[4] Alsufyani, Abdulaziz Mohsen. "Role of theory and research in policy development in health care system." American Journal of Public Health Research 8, no. 2 (2020): 61-66.

[5] Boswell, Christina, and Katherine Smith. "Rethinking Policy 'impact': Four Models of Research-Policy Relations." Palgrave Communications 3, no. 1 (December 2017). doi:10.1057/s41599-017-0042-z..

[6] Sekhri, Sofiane. "The role approach as a theoretical framework for the analysis of foreign policy in third world countries." African Journal of Political Science and International Relations 3, no. 10 (2009): 423-432.

[7] Ingold, Karin. "Network Structures Within Policy Processes: Coalitions, Power, and Brokerage in Swiss Climate Policy." Policy Studies Journal 39, no. 3 (July 27, 2011): 435-459. doi:10.1111/j.1541-0072.2011.00416.x.

[8] James, Thomas E., and Paul D. Jorgensen. "Policy Knowledge, Policy Formulation, and Change: Revisiting a Foundational Question.” Policy Studies Journal 37, no. 1 (February 2009): 141-162. doi:10.1111/j.1541-0072.2008.00300.x.

[9] Puhakainen, Petri, and Mikko Siponen. "Improving employees' compliance through information systems security training: an action research study." MIS quarterly (2010): 757-778. doi:10.2307/25750704. 
[10] Sabatier, P. A. "The Need for Better Theories in Theories of the Policy Process." (1999): 3-17.

[11] Weible, Christopher M., Tanya Heikkila, Peter deLeon, and Paul A. Sabatier. "Understanding and Influencing the Policy Process." Policy Sciences 45, no. 1 (November 18, 2011): 1-21. doi:10.1007/s11077-011-9143-5.

[12] Nowlin, Matthew C. "Theories of the Policy Process: State of the Research and Emerging Trends.” Policy Studies Journal 39 (March 8, 2011): 41-60. doi:10.1111/j.1541-0072.2010.00389_4.x.

[13] Kleinman, Arthur. "Four Social Theories for Global Health." The Lancet 375, no. 9725 (May 2010): 1518-1519. doi:10.1016/s0140-6736(10)60646-0.

[14] Brooks, Thom. "In Defence of Political Theory: Impact and Opportunities." Political Studies Review 11, no. 2 (April 16, 2013 ): 209-215. doi:10.1111/1478-9302.12007.

[15] K. Lewin, "Intention, will and need. In D. Rapaport, Organization and pathology of thought: Selected sources," Columbia Univ. Press, (1951): 95-153.

[16] Teisman, Geert R., and Erik-Hans Klijn. “Complexity Theory and Public Management.” Public Management Review 10, no. 3 (May 2008): 287-297. doi:10.1080/14719030802002451.

[17] Cairney, Paul, Donley T. Studlar, and Hadii M. Mamudu. "Understanding public policy: theories and issues." Public Administration 91, no. 3 (2013): 782-793.

[18] Schlager, Edella, and Christopher M. Weible. "New Theories of the Policy Process." Policy Studies Journal 41, no. 3 (August 2013): 389-396. doi:10.1111/psj.12030.

[19] Lasswell, Harold D. "The Emerging Conception of the Policy Sciences." Policy Sciences 1, no. 1 (1970): 3-14. doi:10.1007/bf00145189.

[20] Birckmayer, Johanna D., and Carol Hirschon Weiss. "Theory-Based Evaluation in Practice.” Evaluation Review 24, no. 4 (August 2000): 407-431. doi:10.1177/0193841x0002400404.

[21] Weiss, Carol H. "Research for Policy's Sake: The Enlightenment Function of Social Research." Policy Analysis 3, no. 4 (1977): 531-45.

[22] Weiss, Carol H. "The Many Meanings of Research Utilization." Public Administration Review 39, no. 5 (1979): 426-31.

[23] Hird, John A. "Policy Analysis for What? The Effectiveness of Nonpartisan Policy Research Organizations." Policy Studies Journal 33, no. 1 (January 27, 2005): 83-105. doi:10.1111/j.1541-0072.2005.00093.x.

[24] Radaelli, Claudio M., and Bruno Dente. "Evaluation Strategies and Analysis of the Policy Process." Evaluation 2, no. 1 (January 1996): 51-66. doi:10.1177/135638909600200105.

[25] Schmidt, Vivien A. "Discursive Institutionalism: The Explanatory Power of Ideas and Discourse." Annual Review of Political Science 11, no. 1 (June 2008): 303-326. doi:10.1146/annurev.polisci.11.060606.135342.

[26] Hall, Peter A. "Policy Paradigms, Social Learning, and the State: The Case of Economic Policymaking in Britain." Comparative Politics 25, no. 3 (April 1993): 275-296. doi:10.2307/422246.

[27] Smith, Kevin B., and Christopher W. Larimer. “The Public Policy Theory Primer.” Westview Press, (2016).

[28] M. Yvonne, “Scopus Indexing: Why all the Fuss?,” IAFOR J. Educ., (2020).

[29] Pan, Xuelian, Erjia Yan, Ming Cui, and Weina Hua. "Examining the Usage, Citation, and Diffusion Patterns of Bibliometric Mapping Software: A Comparative Study of Three Tools." Journal of Informetrics 12, no. 2 (May 2018): 481-493. doi:10.1016/j.joi.2018.03.005.

[30] Virani, Altaf, Adam Wellstead, and Michael P. Howlett. "Where Is the Policy? A Bibliometric Review of the State of Policy Research on Medical Tourism.” SSRN Electronic Journal (2019). doi:10.2139/ssrn.3445235.

[31] Blume, Stuart S. "Policy as Theory: A Framework for Understanding the Contribution of Social Science to Welfare Policy 1." Acta Sociologica 20, no. 3 (July 1977): 247-262. doi:10.1177/000169937702000302.

[32] Caplan, Nathan. “The Two-Communities Theory and Knowledge Utilization.” American Behavioral Scientist 22, no. 3 (January 1979): 459-470. doi:10.1177/000276427902200308.

[33] Rein, Martin. "Methodology for the Study of the Interplay between Social Science and Social Policy." International Social Science Journal 32, no. 2 (1980): 361-68.

[34] Bennett, Colin J. "Regulating privacy: Data protection and public policy in Europe and the United States." Cornell University Press, (1992).

[35] Fay, Daniel L., and Jeffrey B. Wenger. "The Political Structure of Policy Diffusion.” Policy Studies Journal 44, no. 3 (August 13, 2015): 349-365. doi:10.1111/psj.12122.

[36] Virtue, Timothy, and Justin Rainey. “Information Governance and Risk Management.” HCISPP Study Guide (2015): 91-130. doi:10.1016/b978-0-12-802043-2.00005-7.

[37] Taylor, Laura P. "Understanding the FISMA Compliance Process." FISMA Compliance Handbook (2013): $27-40$. doi:10.1016/b978-0-12-405871-2.00004-x.

[38] Wilhelm, Thomas. “Compromising a System and Privilege Escalation.” Professional Penetration Testing (2010): $339-369$. doi:10.1016/b978-1-59749-425-0.00017-8. 
[39] Crossler, Robert E., Allen C. Johnston, Paul Benjamin Lowry, Qing Hu, Merrill Warkentin, and Richard Baskerville. "Future Directions for Behavioral Information Security Research." Computers \& Security 32 (February 2013): 90-101. doi:10.1016/j.cose.2012.09.010.

[40] Moody, Gregory D., Mikko Siponen, and Seppo Pahnila. "Toward a Unified Model of Information Security Policy Compliance." MIS Quarterly 42, no. 1 (January 1, 2018): 285-311. doi:10.25300/misq/2018/13853.

[41] Lowry, Paul Benjamin, and Gregory D. Moody. "Proposing the Control-Reactance Compliance Model (CRCM) to Explain Opposing Motivations to Comply with Organisational Information Security Policies.” Information Systems Journal 25, no. 5 (July 8, 2014): 433-463. doi:10.1111/isj.12043.

[42] Baskerville, Richard, and Mikko Siponen. “An Information Security Meta - policy for Emergent Organizations.” Logistics Information Management 15, no. 5/6 (December 2002): 337 - 346. doi:10.1108/09576050210447019.

[43] Dhillon, Gurpreet, and Steve Moores. "Computer Crimes: Theorizing About the Enemy Within.” Computers \& Security 20, no. 8 (December 2001): 715-723. doi:10.1016/s0167-4048(01)00813-6.

[44] Siponen, Mikko, and Anthony Vance. "Guidelines for Improving the Contextual Relevance of Field Surveys: The Case of Information Security Policy Violations." European Journal of Information Systems 23, no. 3 (May 2014): $289-305$. doi:10.1057/ejis.2012.59.

[45] Vance, Anthony, and Mikko T. Siponen. "IS Security Policy Violations.” Journal of Organizational and End User Computing 24, no. 1 (January 2012): 21-41. doi:10.4018/joeuc.2012010102.

[46] Radaelli, Claudio M. "The Role of Knowledge in the Policy Process.” Journal of European Public Policy 2, no. 2 (June 1995): 159-183. doi:10.1080/13501769508406981.

[47] E. Bardach, “The Implementation Game: What Happens After a Bill Becomes a Law. Cambridge, MA: The MIT Press.," (1977).

[48] Thomas C. Schelling. "T Game Theory: A Practitioner's Approach.” Economics and Philosophy 26, no. 1 (March 2010): 2746. doi:10.1017/S0266267110000040.

[49] Woolcock, Michael, Michael Bamberger, and Vijayendra Rao. "Using Mixed Methods in Monitoring and Evaluation: Experiences from International Development.” SSRN Electronic Journal (2010). doi:10.2139/ssrn.1545914.

[50] Sharkey, Siobhan, and Anne Sharples. "From the Beginning." Evaluation 14, no. 3 (July 2008): 363-380. doi:10.1177/1356389008090860.

[51] Silva, Marta, Luís Pereira Gomes, and Isabel Cristina Lopes. "Explanatory Factors of the Capital Structure." Emerging Science Journal 4, no. 6 (December 1, 2020): 519-529. doi:10.28991/esj-2020-01249.

[52] Scharpf, Fritz W. "Economic Integration, Democracy and the Welfare State.” Journal of European Public Policy 4, no. 1 (January 1997): 18-36. doi:10.1080/135017697344217.

[53] Tomé, Eduardo. "Current and Historical Application of Knowledge Management in Economy." Emerging Science Journal 4 , no. 6 (December 1, 2020): 454-465. doi:10.28991/esj-2020-01245.

[54] Obeidi, Amer, Keith W. Hipel, and D. Marc Kilgour. "Canadian Bulk Water Exports: Analyzing the Sun Belt Conflict Using the Graph Model for Conflict Resolution.” Knowledge, Technology \& Policy 14, no. 4 (December 2002): 145-163. doi:10.1007/s12130-002-1020-2.

[55] Hermans, Leon, Scott Cunningham, and Jill Slinger. "The Usefulness of Game Theory as a Method for Policy Evaluation." Evaluation 20, no. 1 (January 2014): 10-25. doi:10.1177/1356389013516052.

[56] Bulgurcu, Cavusoglu, and Benbasat. "Information Security Policy Compliance: An Empirical Study of Rationality-Based Beliefs and Information Security Awareness.” MIS Quarterly 34, no. 3 (2010): 523-548. doi:10.2307/25750690.

[57] Han, JinYoung, Yoo Jung Kim, and Hyungjin Kim. "An Integrative Model of Information Security Policy Compliance with Psychological Contract: Examining a Bilateral Perspective.” Computers \& Security 66 (May 2017): 52-65. doi:10.1016/j.cose.2016.12.016.

[58] Siponen, Mikko, Seppo Pahnila, and M. Adam Mahmood. "Compliance with Information Security Policies: An Empirical Investigation.” Computer 43, no. 2 (February 2010): 64-71. doi:10.1109/mc.2010.35.

[59] Blackstock, K.L., J. Ingram, R. Burton, K.M. Brown, and B. Slee. "Understanding and Influencing Behaviour Change by Farmers to Improve Water Quality." Science of the Total Environment 408, no. 23 (November 2010): 5631-5638. doi:10.1016/j.scitotenv.2009.04.029.

[60] Jasanoff, Sheila, ed. "States of Knowledge” London: Routledge, (July 31, 2004). doi:10.4324/9780203413845.

[61] D'Arcy, John, and Tejaswini Herath. "A Review and Analysis of Deterrence Theory in the IS Security Literature: Making Sense of the Disparate Findings." European Journal of Information Systems 20, no. 6 (November 2011): 643-658. doi:10.1057/ejis.2011.23.

[62] Li, Han, Jie Zhang, and Rathindra Sarathy. "Understanding Compliance with Internet Use Policy from the Perspective of Rational Choice Theory.” Decision Support Systems 48, no. 4 (March 2010): 635-645. doi:10.1016/j.dss.2009.12.005.

[63] Safarzadeh, Soroush, and Morteza Rasti-Barzoki. "A Game Theoretic Approach for Assessing Residential Energy-Efficiency Program Considering Rebound, Consumer Behavior, and Government Policies.” Applied Energy 233-234 (January 2019): 4461. doi:10.1016/j.apenergy.2018.10.032. 
[64] Son, Jai-Yeol. "Out of Fear or Desire? Toward a Better Understanding of Employees' Motivation to Follow IS Security Policies.” Information \& Management 48, no. 7 (October 2011): 296-302. doi:10.1016/j.im.2011.07.002.

[65] Hall, C. Michael, Allan M. Williams, and Alan A. Lew. "Tourism: Conceptualizations, institutions, and issues." A Companion to Tourism, Oxford, UK: Blackwell Publishing Ltd (2004): 3-21.

[66] Watermeyer, Richard, and Adam Hedgecoe. "Selling 'impact': Peer Reviewer Projections of What Is Needed and What Counts in REF Impact Case Studies. A Retrospective Analysis." Journal of Education Policy 31, no. 5 (April 18, 2016): 651-665. doi:10.1080/02680939.2016.1170885.

[67] Murphy, Tony. "Revising the Research Excellence Framework: Ensuring Quality in REF2021, or New Challenges Ahead?" Perspectives: Policy and Practice in Higher Education 21, no. 1 (November 8, 2016): 34-39. doi:10.1080/13603108.2016.1246386.

[68] Kingdon, John W., and Eric Stano. "Agendas, Alternatives, and Public Policies." Policies Stud. J. 45 (1984).

[69] Dye, Thomas. “Top Down Policymaking” CQ Press (2001). doi:10.4135/9781483330150.

[70] Mackenbach, J. P. "Political Determinants of Health.” The European Journal of Public Health 24, no. 1 (January 24, 2014$): 2-$ 2. doi:10.1093/eurpub/ckt183. 